\title{
Fuzzy Logic Based Energy Efficient Mechanism for Dymo in Mobile AD HOC Networks
}

\author{
K.NarasimhaRaju, Koduru Suresh, Dekka Satish, Pudi Ganesh
}

\begin{abstract}
Mobile ad hoc network (MANET) attracted various researchers in the emerging communication networks without having any centralized structure. In this network, mobile nodes moves in their own wish creating a dynamic topology. Routing is a cumbersome task with this dynamic topology from time to time change in connection pattern. DYMO is emerged as challenging protocol in MANET but works on static configuration parameters such as Hello messages. The mobile device updates the connectivity of their neighbours by sending Hello messages at frequent intervals irrespective of the network scope (terrain) and network elements(number of nodes). As the mobile nodes are battery equipped devices, lot of energy is consumed with these messages. Energy efficient mechanisms are necessary in this type of networks. In this work, DYMOHBFLWTN mechanism is proposed to set the Hello parameter dynamically in DYMO considering network terrain and number of nodes utilizing fuzzy principles. Experiments are conducted on Qualnet 7.0 simulator to evaluate mechanisms - DYMOHBFLWTN and DYMO. The proposed DYMOHBFLWTN mechanism provides better results compared to existing DYMO.
\end{abstract}

Keywords:DYMO, DYMO HBFLWTN, FuzzyLogic, Hello, MANETS.

\section{INTRODUCTION}

In recent communication era, situations such as sudden disasters require deployment of communication instantly. The existing centralized structures require a lot of time to deploy and it is a cost expensive process. In these situations, MANET [1] plays a crucial role.

Ad hoc network provide communication through wireless links without any centralized base. In MANET, the wireless nodes move in their own fashion at each instance. The most advantageous thing in MANET is that it can be deployed with a little interval of time compared to the traditional centralized structures. This flavor attracted so many researchers to create and deploy the MANET environment in different fields. Establishing the routes in this dynamic environment is a major challenging issue. There many routing protocols [2] were developed in this regard but DYMO [3] is one of the popular protocols.

Revised Manuscript Received on December 30, 2019.

* Correspondence Author

Dr. K. Narasimha Raju, Department of Computer Science and Engineering, Lendi Institute of Engineering and Technology, Viziangaram (A.P), India. E-mail: bcoolmind@gmail.com

Koduru Suresh, SAP Labs Bangalore, India.

Email: koduru112@gmail.com,

Dekka Satish , Department of Computer Science and Engineering, Lendi Institute of Engineering and Technology, Viziangaram (A.P), India.

E-mail: satishmtech4u@gmail.com

PudiGanesh, Department of Computer Science and Engineering, Lendi Institute of Engineering and Technology, Viziangaram (A.P), India.

E-mail: ganesh.pudi@gmail.com

(C) The Authors. Published by Blue Eyes Intelligence Engineering and Sciences Publication (BEIESP). This is an open access article under the CC BY-NC-ND license (http://creativecommons.org/licenses/by-nc-nd/4.0/)
The major drawback of DYMO is that it sends Hello message at frequent intervals of time to establish the route ignoring the network scope and network elements. As the mobile nodes are battery equipped devices, lot of energy is consumed with these messages. Therefore, DYMOHBFLWTN method is proposed to set the Hello parameter dynamically with the help of fuzzy logic in DYMO considering network terrain and number of the nodes. Before operating into the real time environment due to cost aspect, the protocols should be analyzed in a simulated environment. In this paper, DYMO and DYMOHBFLWTN are evaluated using Qualnet 7.0 simulator. The next sections of the work are arranged as given here: Section 2 illustrates the brief description of DYMO protocol. A brief related literature in the connected work is presented in Section 3 and Methodology is elaborated in Section 4. Section 5 presents Experimental Evaluation methodology considered for simulation. Results and conclusion are given in Section 6\&7.

\section{DYNAMIC MANET ON DEMAND (DYMO) ROUTING PROTOCOL}

Routing protocols act as an aid to deliver the data packets from an origin to the target. This is a very crucial task in case of MANETs due to random behavior of the mobile nodes and dynamic patterns of the topology. Different routing protocols were developed in MANETs to establish the routes.

The DYMO works with a principle of on-demand basis in MANETs. This protocol sends Hello messages at regular intervals of time frequently to check the connectivity status of the neighbors. To determine the path from the route initiated node to the intended destination, it will send Route Request (RREQ) messages. Once the destination is found, the target node reacts with RREP message to confirm the path. If any link failure occurs on the established path, it is informed via Route Error (RERR) messages to the source from the mobile devices.

\section{RELATEDWORK}

Imrich Chlamtac et.al [4] suggested that instant networks i.e. MANETs will play a key role in upcoming communication era. There are various major challenges to be concentrated are involved in MANET. The establishment of routes in this dynamic network is a major challenge. Several authors [5]made a survey on the routing protocols and observed certain characterstics. S.Corson et.al [6] explained the behavior of routing protocols and analysed the performance consideration in MANET.

Jogendra Kumar et.al [7] analyzed the four routing DSR,AODV,ZRP and DYMO using Qualnet 5.0.2. Evjola Spaho et.al [8] evaluated the DYMO protocol in various scenarios under by varying speed and density in a VANET environment.

Published By: 
Fuzzy Logic Based Energy Efficient Mechanism for Dymo in Mobile AD HOC Networks

Chakeres et al. [9] observed the status of the links established through hello message. The observations are made on AODV routing protocol. They concluded that there are different factors that leads to a change in performance.

Several authors compared various protocols in energy aspect[10]. Lakhan D Sharma et.al [11]analyzed the DYMO,DSR and AODV protocols in some performance metrics using Exata tool.

\section{METHODOLOGY}

DYMO protocol broadcast hello messages at fixed intervals of time to establish the connectivity with their neighbors. At every moment, neighbor information can be known through increasing frequency of hello messages but at the same moment, the network consumes more energy and resources. Decreasing the frequency of these hello messages may result in vague information of their neighbors. Therefore the setting of hello interval should be done properly with respect to network conditions. DYMO operates basing on the static Hello parameters which results in loss of energy. In this paper, the DYMO Hello Based on Fuzzy Logic With respect to Terrain and Nodes (DYMOHBFLWTN) method was proposed to compute dynamic values for the Hello parameter in DYMO using fuzzy logic with respect to terrain and number of nodes.

Logical experiences of a human being can be embedded to a machine through membership functions in fuzzy logic [12]. The Input variables are terrain and number of nodes. Hello Interval is treated as an output variable. Membership functions employed in the model are in shown figures 2,3 and 4. Architecture, rule base and surface view are given in figures 1,5 and 6.

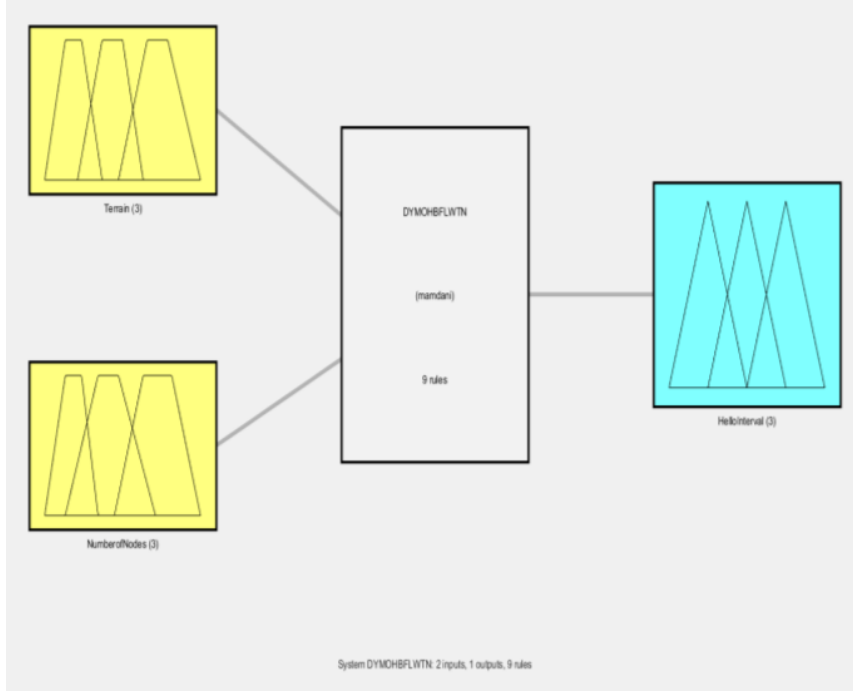

Figure 1 : DYMOHBFLWTN- Mamdani architecture

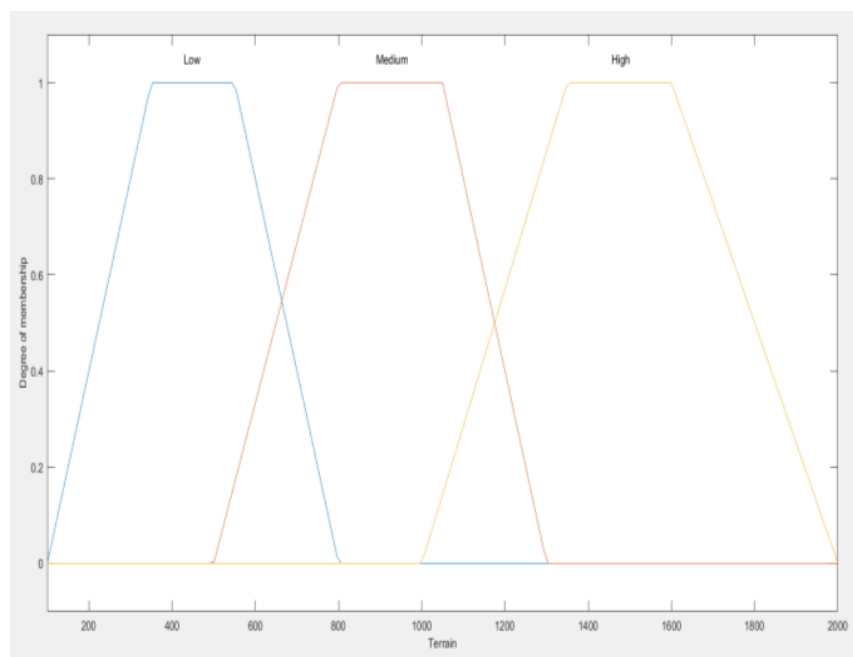

Figure 2: trapezoidal $\mu$ function of terrain

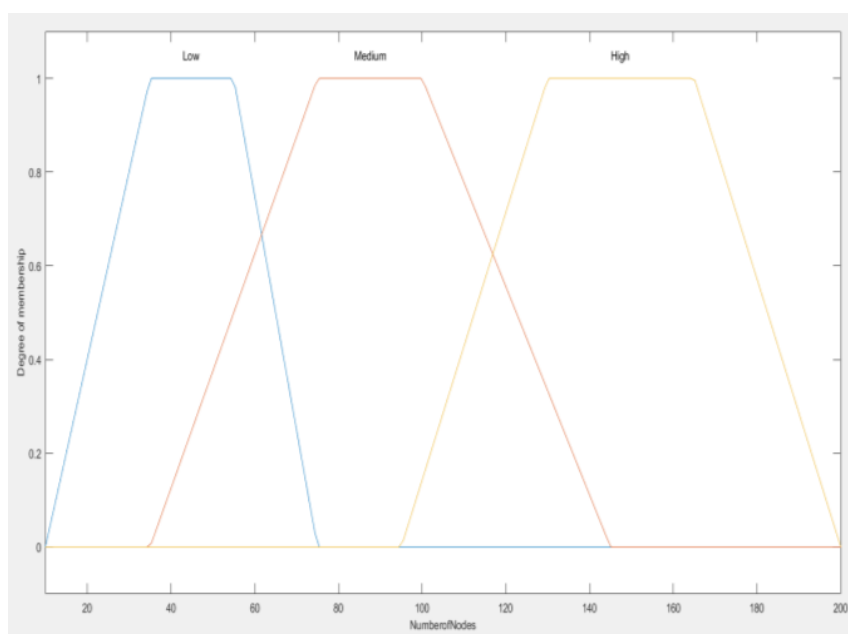

Figure 3: trapezoidal $\mu$ function of Number of nodes

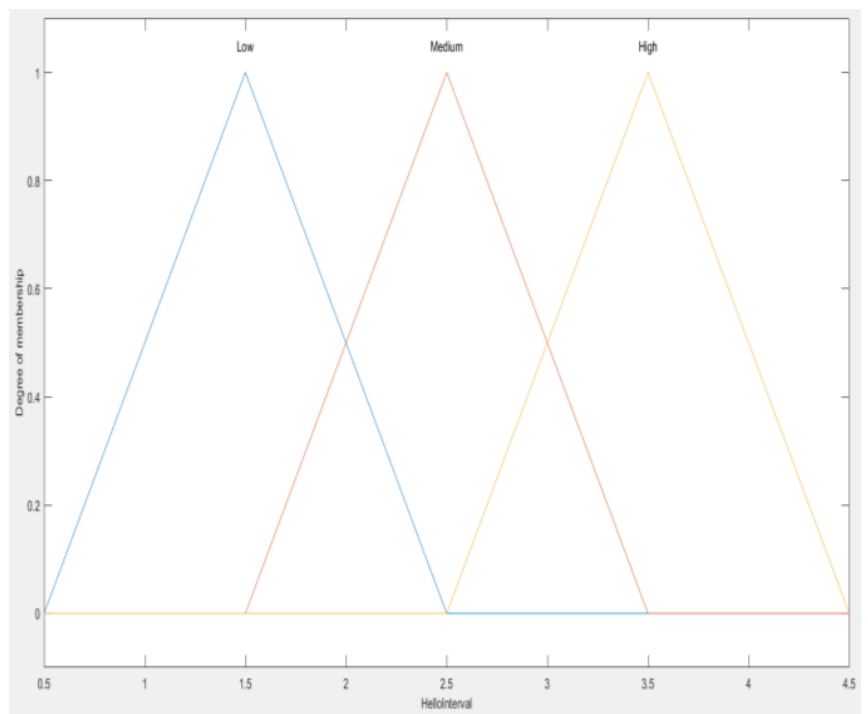

Figure 4 : triangular $\mu$ of 'Hello Interval' 


\section{A. Rule Editor: DYMOHBFWWT}

File Edit View Options

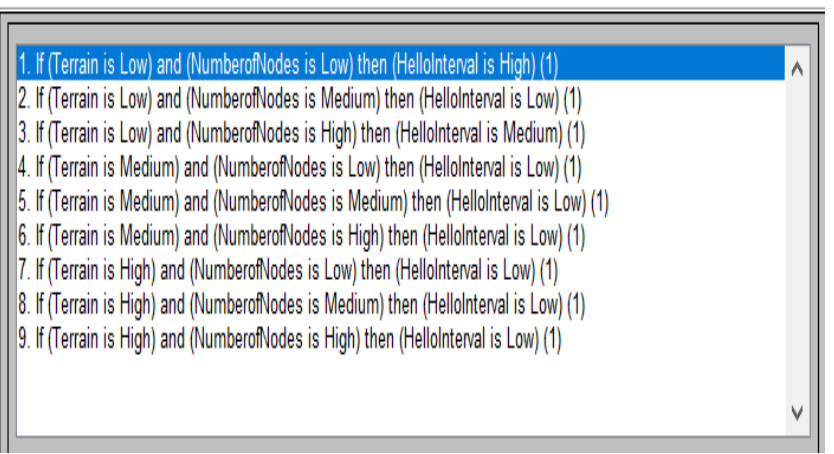

Figure 5: fuzzy rule base of DYMOHBFLWTN

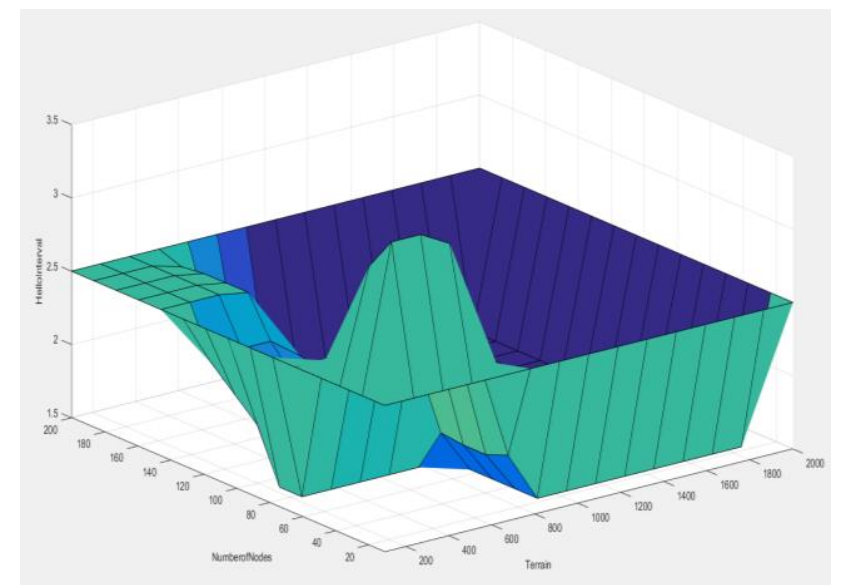

Figure 6: surface view of DYMOHBFLWTN

\section{SIMULATION ENVIRONMENT}

The experimental setup involving real equipment for conducting experiments in MANET is very high expensive. Therefore, a simulation is preferred to know the behavior of the protocols in a low cost way. Many simulators was developed to evaluate the performance of network, but in this paper, Qualnet 7.0 [ 13 ] is used because of its simplicity and rich graphical interface. The experimental details are quoted in the following table 1.

Table 1: Simulation environment of DYMOHBFLWTN

\begin{tabular}{|c|c|}
\hline \multicolumn{2}{|c|}{ Simulation Environment } \\
\hline Area & $1200 \times 1200$ \\
\hline Simulation Time & $600 \mathrm{~s}$ \\
\hline Node Deployment & Random \\
\hline Pause Time & $0 \mathrm{~s}$ \\
\hline Max Speed & $10 \mathrm{~m} / \mathrm{s}$ \\
\hline Traffic & $\mathrm{CBR}$ \\
\hline Number of Items & 100 \\
\hline Item Size & 512 bytes \\
\hline Protocols & 802.11 \\
\hline MAC & DYMO and DYMOHBLWTN \\
\hline
\end{tabular}

\section{RESULTS AND ANALYSIS}

The experiments of DYMO and DYMOHBFLWTN are conducted in Qualnet 7.0. Typical running scenario is shown in the figure 7. The energy evaluation of DYMO and DYMOHBFLWTN are done in Transmit mode(TM) and
Receive mode(RM). The energy required during the transmission of data to other nodes is known as Transmission Energy. The energy consumption in transmit mode is presented in the figure 8 . The energy required during receiving the data from other nodes is known as receiving energy. The energy consumption in receive mode is presented in the figure 9.

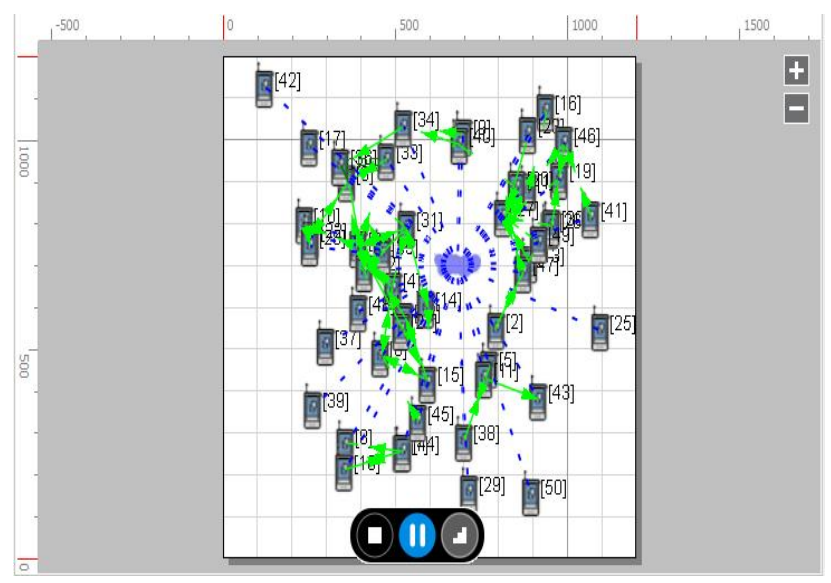

Figure 7: Typical running scenario of DYMOHBFLWTN in Qualnet

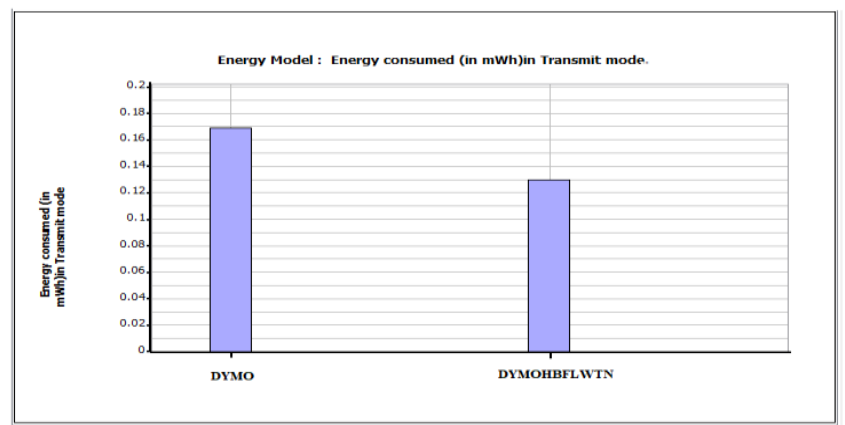

Figure8:Energy consumption of DYMO and DYMOHBFLWTN in Transmit mode

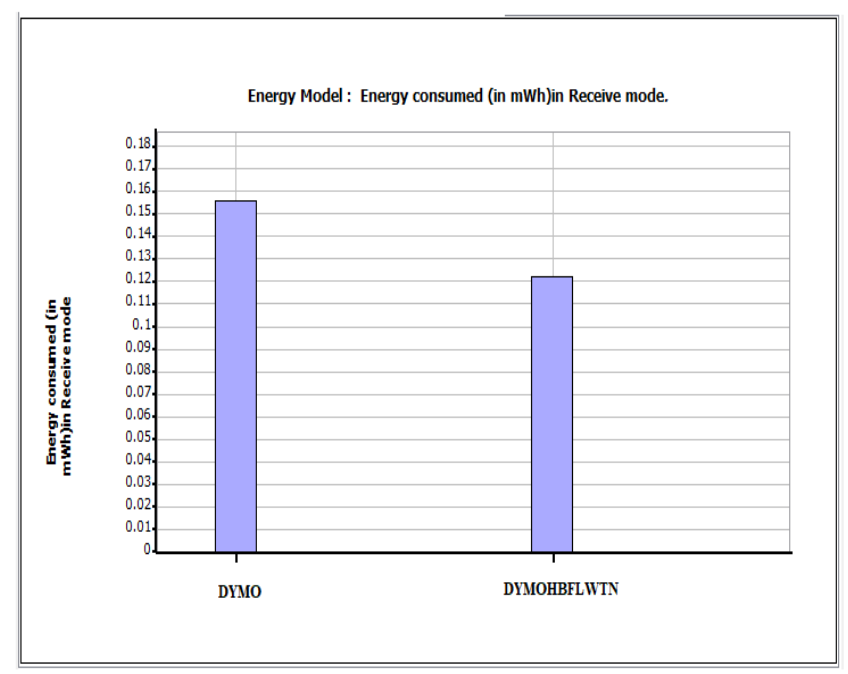

Figure9: Energy consumption of DYMO and DYMOHBFLWTN in Receive mode 
Fuzzy Logic Based Energy Efficient Mechanism for Dymo in Mobile AD HOC Networks

The following table 2 illustrate the energy consumption for DYMO and DYMOHBFLWTN

Table 2: Energy consumption DYMO and DYMOHBFLWTN

\begin{tabular}{|l|l|l|}
\hline Method & TM & RM \\
\hline DYMO & 0.168952 & 0.155784 \\
\hline DYMOHBFLWTN & 0.129886 & 0.122599 \\
\hline
\end{tabular}

\section{CONCLUSION AND FUTURE SCOPE}

Energy consumption occupied a great role in MANETs. The unnecessary frequent updates with hello messages consume a lot of energy during the route establishment of DYMO. The proposed method DYMOHBFLWTN computes dynamic hello interval using fuzzy logic considering terrain and number of nodes. DYMOHBFLWTN works with a less energy consumption compared to DYMO. In future the proposed work can be evaluated in various propagation models.

\section{REFERENCES}

1. Perkins,C.E., Ad Hoc Networking, Chapter 3, pp. 53-74, Addison-Wesley, Jan 2001.

2. Azzedine Boukerche, "Algorithms and Protocols for Wireless, Mobile Ad Hoc Networks", Wiley-IEEE Press, pages 500, Online ISBN: 9780470396384, 2009.

3. Chakeres I, Perkins C (2007) Dynamic MANET on-demand (DYMO) routing. Internet draft, draft-ietf-manet-dymo-11.txt, IETF.

4. Imrich Chlamtac, Marco Conti, and Jennifier J.-N.Liu, "Mobile Ad Hoc Networking: Imperatives and Challenges," Ad Hoc Networks, Elsevier, Volume 1, Issue 1, pages 13-64, July 2003.

5. Srivastava A,Mishra A, Upadhyay B and Yadav A.K., "Survey and overview of Mobile Ad-Hoc Network routing protocols", in proceedings of International Conference on Advances in Engineering and Technology Research (ICAETR), IEEE, pages 1-6, 2014.

6. S.Corson and J. Macker, "Mobile Ad Hoc Networking (MANET): Routing Protocol Performance Issues and Evaluation Considerations", Network working group, RFC 250l. 1999. url: http://www.ietf.org/rfc/rfc2501.txt.

7. Jogendra Kumar et.al, "Study and Performance Analysis of Routing Protocol Based on CBR", Procedia Computer Science, Volume 85 , pp 23-30, Elsevier, 2016

8. Evjola Spaho et.al, "Performance Evaluation of DYMO Protocol in Different VANET Scenarios", in proceedings of 15th International Conference on Network-Based Information Systems, IEEE, 2012.

9. Chakeres I. D. and Royer E. M., "The Utility of Hello Messages for Determining Link Connectivity," in Proceedings of the 5th International Symposium on Wireless Personal Multimedia Communications (WPMC), pp. 504-508, October 2002.

10. J. H Chang and L. Tassiulas, "Energy Conserving Routing in Wireless Ad -hoc Networks", in proceedings of IEEE INFOCOM, 2000, Volume 1, Pages 22-31, March 2000.

11. Lakhan D Sharma and Nirmal Roberts, "Effects of Velocity on performance of DYMO, AODV and DSR routing protocols in Mobile Ad hoc Networks", Elsevier, Procedia Technology, Volume 4, pages 727-731, 2012.

12. L. A. Zadeh, "fuzzy logic = computing with words", IEEE Transactions on fuzzy systems, vol. 4, no2, pp. 104-111, 1996.

13. QualNet Network Simulator: http://www.scalable-networks.com.

\section{AUTHORS PROFILE}

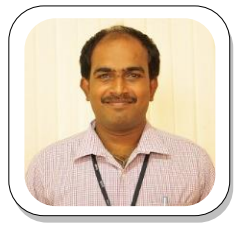

Dr. K.NarasimhaRaju, Professor, CSE Department LENDI, Viziangaram, Expertise and interest include: Computer Networks, Mobile Ad-hoc Networks \& Soft Computing.

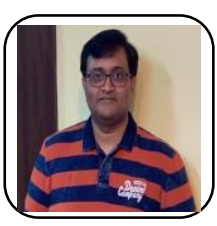

Koduru Suresh, M.Tech.,(Ph.D.), SAP Labs Bangalore, India. Expertise and interest include: Computer Networks, internet of things (IoT) \& Software Development.

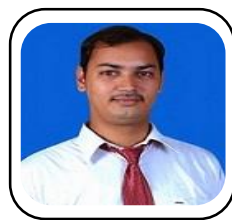

Satish Dekka, M.Tech., (Ph.D.), Associate Professor, CSE Department, LENDI ,Vizianagaram. Expertise and interest Include: Computer Networks, Wireless Sensor networks \& internet of things (IoT).

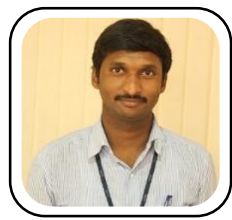

Pudi Ganesh, M.Tech, Assistant Professor, CSE Department, Lendi, Vizianagaram. Expertise and interest include: network security and Data mining. 